\title{
Recovery from aphasia as a function of language therapy in an early bilingual patient demonstrated by fMRI
}

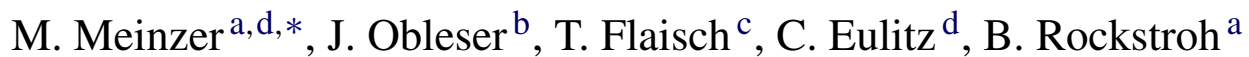 \\ a Department of Clinical Psychology and Neuropsychology, University of Konstanz, 78457 Konstanz, Germany \\ ${ }^{\mathrm{b}}$ Institute of Cognitive Neuroscience, University College London, London WC1N 3AR, UK \\ ${ }^{\mathrm{c}}$ Department of General Psychology, University of Konstanz, 78457 Konstanz, Germany \\ ${ }^{\mathrm{d}}$ Department of Neurolinguistics, University of Konstanz, 78457 Konstanz, Germany
}

\begin{abstract}
Knowledge about the recovery of language functions in bilingual aphasic patients who suffer from left-hemispheric stroke is scarce. Here, we present the case of an early bilingual patient (German/French) with chronic aphasia. Functional magnetic resonance imaging (fMRI) was used to investigate neural correlates of language performance during an overt picture naming task in German and French (a) 32 months after stroke to assess differential recovery of both languages as a function of the preceding language therapy that was provided exclusively in German and (b) after additional short-term intensive (German) language training. At the first investigation behavioral performance confirmed selective recovery of German naming ability which was associated with increased functional brain activation compared to the French naming condition. Changes in behavioral performance and brain activation pattern as disclosed by fMRI after an additional experimental treatment were confined to the trained (German) language and indicate bilateral neuroplastic reorganization. No generalization to the untrained (French) language was observed. The present case results demonstrate use and/or training-dependent differential recovery of expressive language functions and an enhanced pattern of brain activation as a function of the rehabilitation efforts that were focussed exclusively on the patient's German language abilities.
\end{abstract}

Keywords: Language disorder; Stroke; Bilingualism; Treatment; Functional imaging

\section{Introduction}

"Multilingualism" means the mastering and frequent use of two or more languages in everyday life and does not imply a specific degree of proficiency in one or the other language. According to this definition more than half of the world population might be considered multilingual (Fabbro, 2001a). Accordingly, neurological conditions (e.g., stroke, tumors) leading to language disorders may affect more than one language in this population.

Little is known about the recovery of language in multilingual patients suffering from aphasia after neurological injury like cerebrovascular stroke. Former theories of enhanced recovery

\footnotetext{
* Corresponding author at: University of Konstanz, Department of Psychology, Universitätsstr. 10, P.O. Box 23, 78457 Konstanz, Germany. Tel.: +49 7531 884626; fax: +497531882891.

E-mail address: marcus.meinzer@uni-konstanz.de (M. Meinzer).
}

of the "most used language" (Pitres' Rule) or "the native language" (Ribot's law) have not been confirmed (Fabbro, 2001a; Pearce, 2005). Rather, the recovery from aphasia in multilinguals appears to be more complex than these early theories have suggested. For example, Paradis (1987) described six patterns of recovery of aphasia in former bilingual patients. The most frequent are parallel recovery (simultaneous recovery of two or more languages), selective recovery (only one language is recovered) and successive recovery (one language improves before the others). In a more recent study, Paradis (2001) found parallel recovery of both languages in $65 \%$ of patients in a sample of 20 former bilingual patients. Greater impairment of the first acquired language was found in $20 \%$ of the cases, the opposite pattern was observed in the remaining $15 \%$ of the patients. Therefore, a highly variable pattern of recovery is to be expected in bilingual aphasics. Possible influences might be age of acquisition, proficiency and daily use of each language before neurological damage and the training provided following the insult (Marrero, Golden, \& Espe-Pfeifer, 2002). 
Moreover, the question whether rehabilitation efforts are transferred from one language (the trained) to the other (the untrained) language deserves further elaboration. While it has been claimed that rehabilitation efforts usually tend to transfer from the trained to the untrained language to some degree (Fabbro, 2001b; Filiputti, Tavano, Vorano, de Luca, \& Fabbro, 2002; Fredman, 1975; Gil \& Goral, 2004; Watamori \& Sasanuma, 1978), the improvement in the trained language is usually more pronounced than in the untrained language. For example, Junque, Vendrell, Vendrell-Brucet, and Tobena (1989) found more enhanced improvement of naming performance for the trained language in a sample of 30 Catalan-Spanish bilingual aphasics. On the other hand, there are studies that could not demonstrate transfer of treatment efforts from one language to the other: Galvez and Hinckley (2003) investigated a Spanish-English bilingual aphasic patient whose native language was Spanish but rated himself equally proficient in his later acquired English. A naming treatment that included a hierarchy of semantic and phonemic cues or the repetition of target words was provided consecutively in both languages. Improvements were found after each training session for the trained language but no transfer to the untrained language was observed. A possible explanation for the lack of or less pronounced generalization in treatment studies (even in early bilinguals with equal language proficiency) has been provided by Laganaro and Overton-Venet (2001): the authors suggest, that treatment only generalizes when common computational processes (i.e., a task requires the same strategies in both languages) are targeted. This is in line with studies that found more pronounced recovery and enhanced transfer of treatment gains across languages during picture naming treatment for cognates (i.e., words that overlap in form and meaning in different languages) but not for non-cognates (Detry, Pillon, \& de Partz, 2005; Kohnert, 2004; Lalor \& Kirsner, 2001; Roberts \& Deslauriers, 1999). Moreover, Edmonds and Kiran (2006) investigated transfer patterns of a semantic naming treatment that was consecutively provided in English and Spanish in two English-Spanish bilingual aphasics. Transfer from one language to the other was only found in the patient with balanced language skills (i.e., equal premorbid skills for both languages) while no transfer was observed in the (unbalanced) English dominant patient. The authors suggested that for patients who are equally proficient in their language abilities before neurological damage it may be sufficient to treat only one language.

Even though the above cited studies addressed treatment outcome and generalization across languages, to our knowledge the neural concomitants of treatment effects and potential generalization across languages have never been scrutinized by means of functional imaging techniques (e.g., functional magnetic resonance imaging, fMRI). The present study sought to provide such evidence by investigating a 35-year-old early bilingual (German/French) individual with premorbid balanced language skills, who had suffered from a left-hemispheric stroke 32 months ago and was in the late chronic stage of aphasia. After the stroke standard language rehabilitation had been offered which focussed exclusively on the German language abilities.
Functional magnetic resonance imaging (fMRI) during an overt picture naming task using a temporal sparse sampling procedure (Hall et al., 1999) served to monitor cortical activation of verbal responses during scanning. In a first fMRI scan, naming of visually presented objects was required in German and French in order to investigate cortical activation accompanying word-retrieval as a function of the long-term rehabilitation efforts. Then, the patient participated in a 2-week intensive (German) language training (Meinzer, Djundja, Barthel, Elbert, \& Rockstroh, 2005; Pulvermueller et al., 2001). Special emphasis was given to word-retrieval in this training. Functional MRI was repeated for both languages after the training period to explore neuroplastic changes, i.e., concomitants of improvement of function, and potential transfer of training to French.

\subsection{Case history}

$\mathrm{CQ},{ }^{1}$ a highly educated (Ph.D.) right-handed 35-year-old man was raised as the son of a German father and a French mother in France until the age of 3. The primary language during the first 3 years of his life was French, but he became fluent in German by the age of 3 when the family moved to Germany where he visited a German Kindergarten and spent most time with his grandparents who only spoke German. The primary language with his parents was French. Therefore, both languages were used on a daily basis during his early childhood. According to the patient and his parents language skills for each language were comparably good. Until he graduated from high-school both languages were equally prominent in his everyday life, German at school and French at home. Later in life the patient continued to use both languages on a daily basis at home and at work, since he was employed at an international law firm. ${ }^{2}$

At the age of $32 \mathrm{CQ}$ suffered from an ischemic cerebrovascular stroke of the left middle cerebral artery following dissection of the internal carotid artery. Two weeks later decompressive craniectomy was performed since additional intralesional bleeding was encountered during computer tomography and a left frontal ventricular catheter was introduced. An additional 2 weeks later the catheter was removed and the site of trepanation was closed by a palakosplastic. The remaining lesion involved large parts of fronto-temporo-parietal lobes of the left hemisphere. The anterior portion of the middle and superior temporal lobe, the inferior frontal gyrus and rolandic operculum, pre- and postcentral regions, the posterior portion of the insula and putamen and parts of the superior and inferior parietal lobe (determined from Talairach \& Tournoux, 1988) were affected. The posterior portion of the superior and middle temporal lobe and inferior temporal regions remained largely spared (see Fig. 1 for details of the lesion).

In the acute phase, CQ's (German) language disorder was diagnosed as global aphasia. According to CQ and his parents,

\footnotetext{
${ }^{1}$ Initials were changed in order to guarantee confidentiality.

${ }^{2}$ Later in life, during high-school education and at university, the patient also acquired English and Italian. We do not report on his other languages, since they were not acquired at an early age.
} 


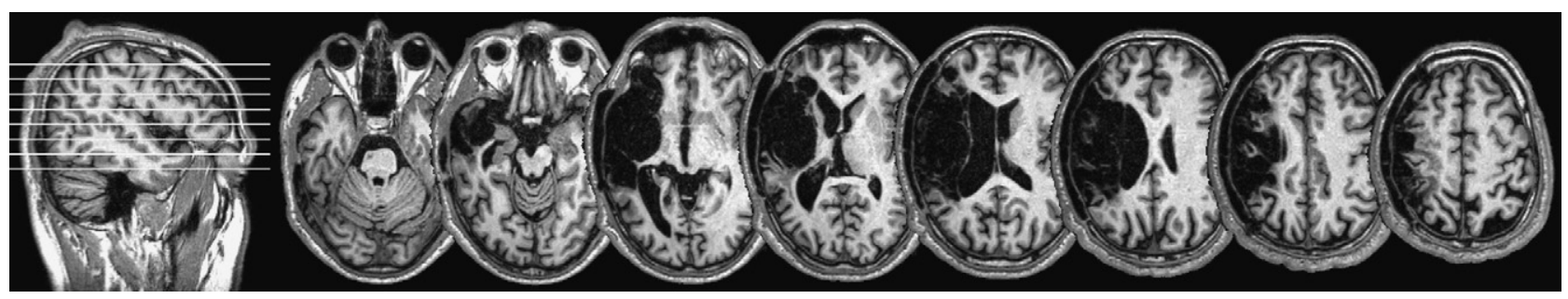

Fig. 1. Shows the patient's lesion (axial slices, T1-weighted MR scan, left =left).

comprehension was regained for all languages over the next 3 months even without any formal training of French, English and Italian. Eighteen months post-stroke, CQ was diagnosed as severe Broca's aphasia following the diagnostic criteria of the Aachen Aphasie Test (AAT, Huber, Poek, Weniger, \& Willmes, 1983). Severe word-retrieval problems were evident, although he was able to utter three to five word phrases. Standard speech and language therapy across the first 32 months after stroke included different treatment approaches [e.g., stimulation by various means (Duffy, 1986), model-based therapy (Nickels, 2002) and communicative approaches (Davis \& Wilcox, 1985)]. These long-term rehabilitation efforts have been provided exclusively in German at an intensity of approximately $3 \mathrm{~h} / \mathrm{week}$. The patient's relatives and friends only spoke German with him according to advice of the responsible speech and language pathologist.

CQ was examined in our unit 32 months after the stroke. Using the Aachen Aphasia Test, his (German) aphasic syndrome was determined as moderate amnestic aphasia with predominantly syntactic and word-retrieval difficulties. No pathological "mixing" (mixing of different languages within one utterance) or "switching" (alternation of languages between utterances) was evident in the diagnostic assessment (which was accomplished in German).

\section{Materials and methods}

\subsection{Language training and testing}

The patient was tested before (pre) and after (post) a short-term intensive (experimental) language training (Constraint-Induced Aphasia Therapy, CIAT, Meinzer et al., 2005; Pulvermueller et al., 2001) that was accomplished in German. The development of CIAT has been guided by neuroscientific knowledge about cortical plasticity and includes a heavy training schedule $(3 \mathrm{~h} /$ day on 10 consecutive workdays) within a motivating setting. This is achieved by way of communicative language games in an interactive group setting. Communication was "constrained" to spoken language. A therapist is present to help patients, whenever problems arise during the game (e.g., by prompting with the first letter in case of word-finding difficulties or by means of semantic cues). Improvements in language abilities were systematically shaped by increasing levels of task difficulty adjusted to the individual patient's capacities.

Language performance in German was assessed by the standard German neuropsychological language test (Aachen Aphasia Test, AAT) and by a selfdeveloped naming test that included 150 photographic objects. Naming of the objects was required without response time restriction, while the first response was scored. Using the same stimuli in a different sequence, word-retrieval in French was assessed in the same test sessions before and after training. At the time of training no standardised test battery for aphasia was available for the French language.

\subsection{Functional MRI assessment}

Magnetic resonance imaging was performed using a $1.5 \mathrm{~T}$ scanner (Philips Intera) at the local neurorehabilitation center (Kliniken Schmieder, Allensbach). Functional MRI stimulation consisted of two blocked conditions of overt picture naming which alternated with passive fixation of a cross at the center of the screen. Conditions (overt naming, passive fixation) were presented in blocks of five consecutive trials, with the sequence of picture naming blocks being identical for both assessments while picture sequence varied within each block. A total of 16 blocks for each condition were collected (80 naming trials, 80 fixation trials). Pictures were taken from an internet database (Szekely, Jacobsen, D'Amico, \& Devescovi, 2004) and included line drawings of objects. Forty of these pictures were included in the training material to be named once in each daily training session. Stimuli were presented by a visor (VisuaStim, Resonance Technology Inc.) for $3 \mathrm{~s}$, and overt naming was required during this interval. After a delay of $.8 \mathrm{~s}$ a whole-brain functional MR volume was acquired (temporal sparse sampling, Hall et al., 1999). Functional MR echoplanar imaging (EPI) was performed with the following acquisition parameters: repetition time $\mathrm{TR}=6 \mathrm{~s}$; acquisition time $\mathrm{TA}=2.2 \mathrm{~s} ; 28$ transversal slices, slicethickness: $4.5 \mathrm{~mm}$; in-plane resolution: $3.6 \mathrm{~mm} \times 3.6 \mathrm{~mm}$, field of view $=230$, acquisition matrix $64 \times 64$. A total of 160 functional whole-brain volumes were acquired.

Within two scanning sessions scheduled on the same day, the naming of the same pictures was accomplished once in German (first) and once in French (second). Two alternative sequences of blocks were used for the two languages. Verbal responses were transmitted from the scanner to a microphone, taperecorded and transcribed after scanning. No overt response was required for the control condition (fixation). Written informed-consent was obtained from CQ. The study was approved by the Local Ethics Committee and in accordance with the Helsinki Declaration.

\subsection{Functional MRI pre-processing}

Functional MRI pre-processing was performed using Statistical Parametric Mapping (SPM2, Wellcome Department of Cognitive Neurology, London, UK) and included standard SPM slice-timing, realignment, normalization and smoothing $(9 \mathrm{~mm} \times 9 \mathrm{~mm} \times 12 \mathrm{~mm}$ Gaussian Kernel) routines. During normalization, however, cost-function masking was performed to prevent distortion of the image due to the lesion (Brett, Leff, Rorden, \& Ashburner, 2001). Data were modeled using a finite impulse response function (Gaab, Gabrieli, \& Glover, 2006). Anatomical localization of significant voxels within clusters was conducted with the Talairach Demon software using the nearest grey matter option (Lancaster et al., 2000).

Statistical analysis included:

A. Investigation of the impact of long-term rehabilitation efforts in German on activation patterns before the present assessments:

1. Main contrasts were calculated for each language (French and German) before training (pre) during overt picture naming $\left(\right.$ German $_{\text {pre }}>$ Fixation; French $_{\text {pre }}>$ Fixation).

2. Since main contrasts revealed larger activations for German as compared to French during picture naming, we also directly contrasted naming in German and French controlling for baseline brain activity $\left[\left(\right.\right.$ Naming $_{\text {German }}-$ Fix $)>\left(\right.$ Naming $_{\text {French }}-$ Fix $\left.)\right]$ both at pre-training. 
B. Investigation of the impact of short-term intensive training in German and the potential transfer to French:

1. Main contrasts were calculated for both sessions (before and after training: pre/post) separately for each language. Increased activation after therapy was evaluated as [(Naming-Fix $\left.)_{\text {post }}>(\text { Naming-Fix })_{\text {pre }}\right]$. Increased activation during the first session (before therapy) compared to the second session (after therapy) for each language was scrutinized with the inverse contrast.

Voxel thresholds for all contrasts were set to $p<.05$ family-wise error corrected (FWE) with a cluster threshold of $k>25$. Coordinates and statistical values for peak voxels within significant clusters are reported.

C. Post hoc analyses: Since we found increased activation after treatment for German but not for French a post hoc analysis was performed to confirm a larger increase of activation across time for German compared to French in a time $\times$ language interaction $\left[\left(\mathrm{German}_{\text {post }}-\mathrm{Fix}\right)-\left(\mathrm{German}_{\text {pre }}-\mathrm{Fix}\right)\right]$ $>\left[(\right.$ French post - Fix $)-\left(\right.$ French $_{\text {pre }}-$ Fix $\left.)\right]$. The threshold for this contrast was set to $p<.005$ uncorrected with a cluster extent of $k>25$.

\section{Results}

\subsection{Language performance}

Before training, German responses in the overt fMRI picture naming task (including a total of 80 pictures) were classified as correct $(N=38)$, semantic paraphasias $(N=22)$, and "don't know responses" $(N=17 / 80)$, while only one phonemic error was noted. Switching phenomena [e.g., the Italian "ponte" instead of the German "Brücke" for "bridge"] occurred twice. In contrast, only four pictures were named correctly in French, while most responses were "don't know responses" $(N=68 / 80)$. Infrequently, the patient named pictures in German or Italian $(N=2)$ and six semantic paraphasias ["cheval" (horse) instead of "zebre" (zebra)] occurred.

CIAT improved performance in the German naming task from 38 to 54 correctly named pictures, while the number of semantic paraphasias decreased after therapy (pre/post: 22/10). The number of correct responses in French remained low during both investigations (pre/post: 4/6). Results of Ger- man and French naming performance are summarized in Table 1.

This pattern was confirmed by performance in the repeated naming test that was performed without any fMRI scanning. Naming in German further improved from 80 to 109 (out of 150) correctly named pictures after training, while correct naming responses in French increased only marginally from 15 to 17 items.

Recovery of CQ's German aphasia after CIAT was further substantiated by significant improvement in the profile score and the Token Test of the AAT, which serve as measures of the global severity of aphasia (pre/post profile score: 52.8/55.4; Token Test raw score: $32 / 17$ errors), as well as the subscales 2 and 4 of the AAT-naming subtest (pre/post: naming of colors 21/27 points; naming of situations: $15 / 20$; the entire naming subtest only marginally failed to reach significance $75 / 89$ points).

\subsection{Functional MRI results}

Before training, German picture naming (compared to fixation) elicited activation in a large, mainly right-hemispheric, network that included occipital, fronto-temporal and parietal regions (Fig. 2). In contrast, activation by French naming attempts was confined to occipital and fronto-parietal regions and the frontal activation pattern appeared less pronounced compared to German. No activation was found in temporal areas (see Table 2 for details).

More pronounced activation by German compared to French picture naming before training was substantiated for the right superior temporal sulcus (STS) and middle temporal gyrus (MTG), i.e., areas homologue to the left-hemispheric areas affected by the lesion. This cluster $(k=82)$ was located in the STS (peak activation $x=52, y=-26, z=-2, T=6.7$ in STS), although extending mostly into the middle temporal gyrus $(73 \%$ of the activated voxels were located in the MTG). No signifi-

Table 1

Test performance during fMRI in the overt picture naming task for German and French

\begin{tabular}{|c|c|c|c|c|c|c|c|c|c|c|}
\hline & \multicolumn{10}{|l|}{ German } \\
\hline & \multicolumn{5}{|c|}{ Before training } & \multicolumn{5}{|c|}{ After training } \\
\hline & Correct & $\begin{array}{l}\text { Semantic } \\
\text { error }\end{array}$ & $\begin{array}{l}\text { Phonemic } \\
\text { error }\end{array}$ & $\begin{array}{l}\text { Don't know } \\
\text { responses }\end{array}$ & $\begin{array}{l}\text { Switching }{ }^{\mathrm{a}} \\
\text { (French/Italian) }\end{array}$ & Correct & $\begin{array}{l}\text { Semantic } \\
\text { error }\end{array}$ & $\begin{array}{l}\text { Phonemic } \\
\text { error }\end{array}$ & $\begin{array}{l}\text { Don't know } \\
\text { responses }\end{array}$ & $\begin{array}{l}\text { Switching } \\
\text { (French/Italian) }\end{array}$ \\
\hline Trained & 18 & 12 & 1 & 8 & 1 & 35 & 2 & 0 & 4 & 0 \\
\hline Untrained & 20 & 10 & 0 & 9 & 1 & 19 & 8 & 0 & 11 & 1 \\
\hline Total $^{b}$ & 38 & 22 & 1 & 17 & 2 & 54 & 10 & 0 & 15 & 1 \\
\hline
\end{tabular}

French

\begin{tabular}{lllll}
\hline \multicolumn{2}{l}{ Before training } \\
\hline Correct & $\begin{array}{l}\text { Semantic } \\
\text { error }\end{array}$ & $\begin{array}{l}\text { Phonemic } \\
\text { error }\end{array}$ & $\begin{array}{l}\text { Don't know } \\
\text { responses }\end{array}$ & $\begin{array}{l}\text { Switching } \\
\text { (German/Italian) }\end{array}$
\end{tabular}

After training

\begin{tabular}{lllll}
\hline Correct & $\begin{array}{l}\text { Semantic } \\
\text { error }\end{array}$ & $\begin{array}{l}\text { Phonemic } \\
\text { error }\end{array}$ & $\begin{array}{l}\text { Don't know } \\
\text { responses }\end{array}$ & $\begin{array}{l}\text { Switching } \\
\text { (German/Italian) }\end{array}$
\end{tabular}

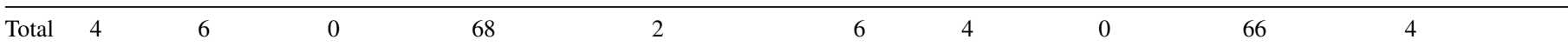

a "Switching" phenomena here refers to semantically correct word-retrieval during fMRI in the wrong language.

b Half of the stimuli were trained during the 2-week intensive training period, therefore German responses can be subdivided in trained and untrained stimuli. 

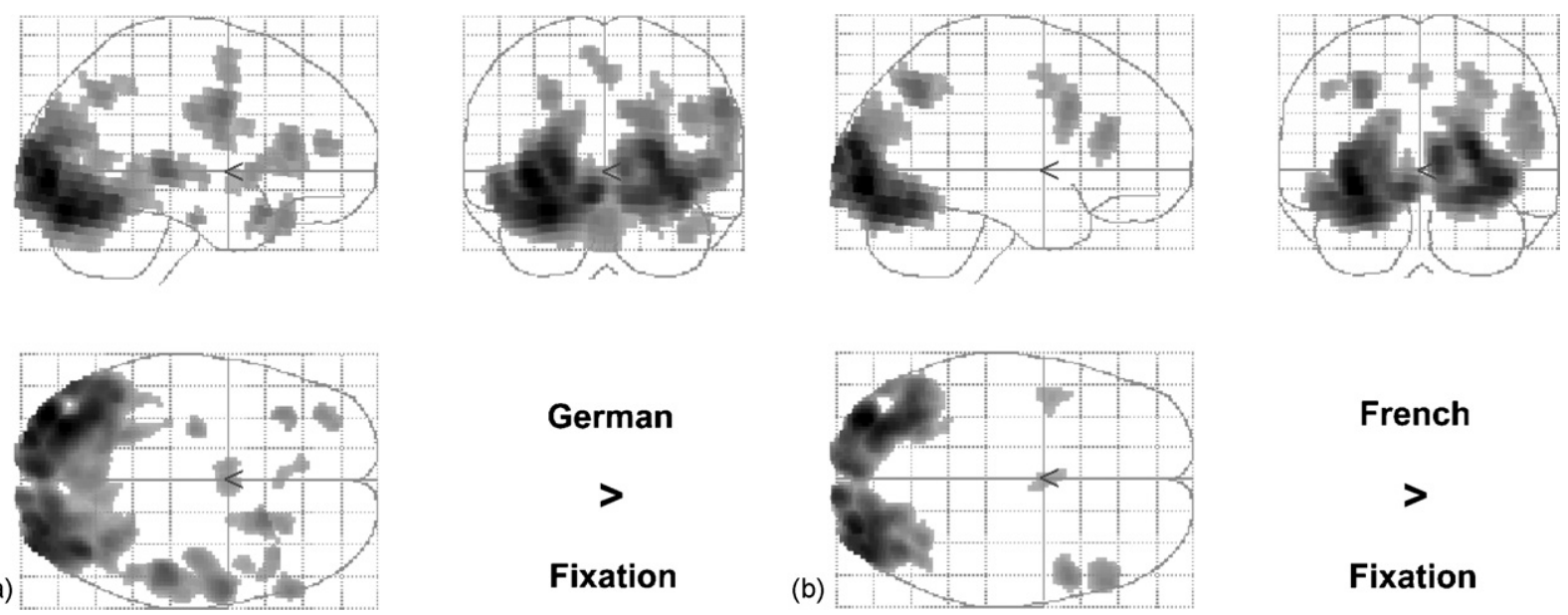

French

Fig. 2. SPM-glass brain depiction of the activation pattern at the first investigation for the (a) German and (b) French version of the naming task during fMRI compared to the baseline condition $(p<.05$, FWE-corrected, $k>25)$.

Table 2

Summary of the fMRI activation pattern for the main contrasts (Naming ${ }_{\text {German }}>$ Fixation; Naming French $>$ Fixation) at the first investigation

\begin{tabular}{|c|c|c|c|c|c|c|c|c|c|c|c|c|c|}
\hline \multirow[t]{2}{*}{ Region } & \multirow[t]{2}{*}{ Hemi } & \multicolumn{6}{|c|}{ German > Fixation } & \multicolumn{6}{|c|}{ French $>$ Fixation } \\
\hline & & $\mathrm{BA}$ & $k$ & $x$ & $y$ & $z$ & $T$ & $\mathrm{BA}$ & $k$ & $x$ & $y$ & $z$ & $T$ \\
\hline \multicolumn{14}{|l|}{ Occipital } \\
\hline Lingual gyrus & $\mathrm{R}$ & 18 & 44 & 9 & -64 & 3 & 6.41 & 18 & 1302 & & -85 & -18 & 11.54 \\
\hline \multicolumn{14}{|l|}{ Temporal } \\
\hline Superior temporal & $\mathrm{R}$ & 216 & 264 & 50 & -24 & -4 & 10.61 & & & & & & \\
\hline \multicolumn{14}{|l|}{ Frontal } \\
\hline Middle frontal & $\mathrm{R}$ & & & & & & & 9 & 140 & 48 & 16 & 35 & 7.16 \\
\hline & & & & & & & & 46 & 95 & 50 & 36 & 18 & 7.07 \\
\hline Medial frontal & $\mathrm{L}$ & 6 & 80 & 2 & -6 & 61 & 6.65 & 6 & 49 & 0 & 0 & 58 & 6.23 \\
\hline Inferior frontal & $\mathrm{R}$ & 46 & 57 & 53 & 38 & 9 & 6.91 & & & & & & \\
\hline Precentral & RL & 6 & 341 & 56 & 2 & 36 & 11.27 & 4 & 43 & -45 & -9 & 50 & 6.42 \\
\hline & $\mathrm{R}$ & 7 & & & & & & 7 & 90 & 33 & -62 & 47 & 6.99 \\
\hline
\end{tabular}

$\mathrm{L}=$ left, $\mathrm{R}=$ right; Hemi = Hemisphere; $\mathrm{BA}=$ Brodman Area; $k=$ cluster extent; $x / y / z=$ Talairach-coordinates and $T$-values referring to maximally activated voxel for each significant cluster; voxel threshold $p<.05$ FWE-corrected, $k>25$, anatomic structures have been determined using the nearest grey matter option of the Talairach Demon software (Lancaster et al., 2000).

cant differences for the inverse contrast (French > German) were found.

After training, German naming additionally activated frontotemporal areas of both hemispheres, as confirmed by the comparison of activity patterns across assessments (Table 3 ), while no differences could be substantiated for (the untrained) French. No enhanced activation in pre- compared to post-training was observed for either language.

The interaction time $\times$ language confirmed the differential effect of therapy on brain activation in the two languages. Increase of activation was more pronounced for German in right and left frontal areas (left medial frontal: $x=-12, y=53$, $z=6, T=5.4 ; k=551$; right medial frontal: $x=24, y=39, z=26$; $T=4.89 ; k=301$; right inferior frontal: $x=36, y=20, z=-14$;
$T=4.7 ; k=242)$ and the right inferior parietal lobe $(x=45$, $y=-59, z=47 ; T=3.8 ; k=214$ ).

\section{Discussion}

In the present case report functional imaging allowed us to disclose the neural substrate of training-induced differential recovery of lexical access and production. This differential aspect was emphasized by training only one language in a formerly bilingual person. The overt picture naming task allowed the observation of the actual performance of the patient during scanning - that is, the brain activation can be monitored in parallel with the actual process or function. 
Table 3

Summary of bilaterally increased functional activation after therapy (post $>$ pre) during the German version of the overt naming task

\begin{tabular}{|c|c|c|c|c|c|c|c|}
\hline Region & Hemi & BA & $k$ & $x$ & $y$ & $z$ & $T$ \\
\hline \multicolumn{8}{|l|}{ Temporal } \\
\hline Inferior temporal & $\mathrm{L}$ & 20 & 79 & -56 & -10 & -30 & 6.91 \\
\hline \multicolumn{8}{|l|}{ Frontal } \\
\hline Superior frontal & $\mathrm{R}$ & 9 & 35 & 9 & 51 & 25 & 7.48 \\
\hline \multirow[t]{3}{*}{ Medial frontal } & $\mathrm{R}$ & 98 & 45 & 24 & 36 & 20 & 6.16 \\
\hline & & 8 & 27 & -9 & 37 & 42 & 6.14 \\
\hline & $\mathrm{L}$ & 8 & 36 & -15 & 50 & 9 & 6.85 \\
\hline Middle frontal & $\mathrm{L}$ & 47 & 66 & -30 & 38 & -4 & 5.50 \\
\hline Anterior cingulate & $\mathrm{R}$ & 32 & 58 & 18 & 43 & -10 & 8.95 \\
\hline \multicolumn{8}{|l|}{ Occipital } \\
\hline Occipital (Cuneus) & $\mathrm{R}$ & 18 & 63 & 6 & -92 & 21 & 6.73 \\
\hline
\end{tabular}

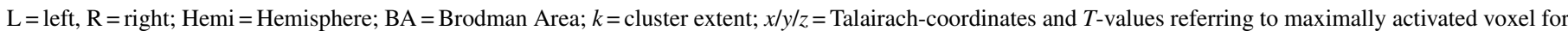

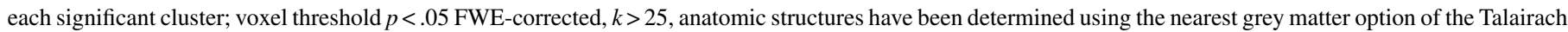
Demon software (Lancaster et al., 2000).

In pre-training data, the activation pattern induced by naming in German and in French reflects the effects of the preceding standard rehabilitation efforts, which had extended across the 32 months since the stroke and which were exclusively focused on the German language. Indeed, better performance in the naming task in German (compared to French) was accompanied by distinct patterns of activation. The most pronounced difference between the two languages at the pre-training period was seen in the right superior temporal sulcus/middle temporal gyrus, that is, in areas homologous to those affected by the left-hemispheric lesion. Activation in left-hemispheric superior and middle temporal cortices is related to semantically driven lexical search and has consistently been reported for tasks that involve verbal production (Fiez, Raichle, Balota, Tallal, \& Petersen, 1996; Murtha, Chertkow, Beauregard, \& Evans, 1999). Further evidence points to activation of homologue right-hemispheric regions during lexical semantic processing in healthy subjects and aphasics alike (Cappa, 2000; Leger et al., 2002; Murtha et al., 1999; Musso et al., 1999). For example, Cardebat et al. (2003) used positron emission tomography (PET) in the study of changes of brain activation during long-term recovery (from 2 months post-stroke to $>12$ months) of aphasia using verb and noun generation tasks. Increased activation in superior temporal regions of both hemispheres was associated with improved language performance at rescanning after 1 year. Still, functional neuroimaging of language in normal subjects may show a set of brain regions whose activation is related to the task, but not actually "necessary" for its performance (Price, Mummery, Moore, Frakowiak, \& Friston, 1999). The activations observed in the right hemisphere during language tasks may have a functional significance, without being necessary for their execution. Accordingly, they could reflect the persistent automatic activation of a subsidiary language, whose function is inhibited by the preponderant left-sided system. Noteworthy, this "dormant" system could partially compensate for the effects of left-sided lesion and aphasia, at some stages of recovery.

In the present study, activation of the right superior temporal lobe was substantiated for German but not French naming.
This increased activation may well be an effective contribution to the recovery of function as induced by long-term speech and language therapy, and the language-differential activation pattern seen in the superior temporal regions might account for the enhanced recovery of German in contrast to the poor naming performance for French. Still, other factors next to the treatment provided might have contributed to the differential activation pattern found at the first investigation. For example, we were not able to investigate the patient's language abilities for French and German and related activation patterns immediately after the stroke (i.e., prior to the long-term treatment interval). Therefore, we cannot completely rule out that a more pronounced activation pattern for German was already present at an early post-stroke stage. In the same vein, it might even be argued that the absence of exposure or use of French would even have inhibited using this language. Evidence for this assumption comes from a study by Pallier et al. (2003): in this study, a sample of adult Korean subjects who were adopted by French families early in life was investigated using fMRI while listening to sentences in French, Korean and other languages they were not capable of. The brain activation pattern elicited by Korean sentences resembled that of the "other languages", while the activation pattern of the later and perfectly acquired French was comparable between the Korean subjects and native speakers of French.

Furthermore, one might argue that the large difference between the two conditions in temporal areas is related to the auditory processing of the subject's own articulation. While picture naming in German was often accompanied by articulation, during the French naming task most responses were accompanied by silence or "don't know" responses. Thus, there might have been a difference in the total amount of auditory processing demands for the two conditions, and since we did not ask the patient to make a standard utterance if he could not name a picture, this explanation cannot be ruled out entirely. However, STS and MTG are functionally and anatomically clearly distinct from more basal auditory processing areas in superior temporal gyrus where perception of one's own voice would be expected to yield activation (e.g., Fu et al., 2006). Still, the 
inclusion of a more complex baseline task would not only have solved the issue of auditory feedback, it would also have allowed to investigate, whether the fMRI pattern reflected problems in word finding, phonetic production, or a combination of the two, which could not be addressed with the design of the present study.

A short-term intensive (experimental) training that was performed in German further improved naming and reduced aphasia severity. This improvement of language functions 32 months after stroke can be attributed to the training, as no further spontaneous improvements of language functions in aphasia are to be expected in such a late chronic stage of aphasia (Robey, 1998). Improved naming performance during fMRI was accompanied by increased activation in perilesional and contralesional regions for the trained/improved (German) language, while the activation pattern of the untrained/unimproved (French) language remained unchanged. This was confirmed by the post hoc analysis that directly compared the change of activation across time, and it also revealed more pronounced activation bilaterally for the German compared to the French naming condition in frontal (inferior and medial frontal areas) and inferior parietal areas.

Our results indicate that training-induced plastic changes of brain functions may not generalize to naming performance in other languages, not even in an early bilingual subject who had acquired the other language before the age of 3 years and used both languages on a regular basis until the onset of aphasia. However, the results of the present study are based on a single patient and the severity of aphasia was different across the two languages. In addition, given the large perisylvian lesion, the pattern of recovery from aphasia in German seems to be atypical (moderate amnestic aphasia instead of the expected severe Broca's aphasia). The enhanced recovery potential in this patient might have been be mediated by the fact that bilingual patients have more bilateral organization of language networks per se (for a recent review see Hull \& Vaid, 2006) and possibly be related to the reactivation of previously inhibited righthemispheric brain structures (due to transcallossal inhibition). Moreover, there is no standardized version of the AAT for French which would have allowed a direct comparison of the patient's German and French language skills other than naming. Even though out of the scope of this report, we can therefore not rule out some transfer to the second language for other language functions than word-retrieval. Unfortunately, a more specialized test battery which would have allowed a direct comparison between different languages (e.g., Bilingual Aphasia Test, BAT, Paradis, 2001), was not available at our institution at the time of testing.

In general, there is considerable variability in brain areas responsible for recovery of language functions in aphasic patients. Several previous studies that investigated naming performance in aphasia (e.g., Fernandez et al., 2004; Perani et al., 2003) found enhanced recovery of language functions to be related to reintegration of left-hemispheric (perilesional) brain regions. Moreover, even though the critical role of right-hemispheric areas to recovery have also been emphasized (Crosson et al., 2005), others have interpreted increased contralesional activation in aphasia as a compensatory/dysfunctional mechanism (e.g., Naeser et al., 2005). Training-related reorganization of language following CIAT in the chronic stage of aphasia has previously been reported in perilesional areas (Meinzer et al., 2004) and bilaterally (Meinzer et al., 2006; Pulvermuller, Hauk, Zohsel, Neininger, \& Mohr, 2005). In line with these findings, the present study disclosed increased activation for the German naming task mainly in perilesional inferior temporal and medial frontal regions and right-hemispheric areas homologue to the lesion after 2 weeks of intensive training. The increased activation in perilesional areas is consistent with activation of a large network involved in semantic processing found in healthy subjects during picture naming tasks (Murtha et al., 1999), while activation in the right anterior cingulate gyrus might be related to response monitoring and increased cognitive control during lexical retrieval (Kerns et al., 2004). Furthermore, the middle and medial frontal cortices have been linked to controlled retrieval of sematic information from working memory, while inferior temporal areas have been implicated with retrieval of associative knowledge (Sharp, Scott, \& Wise, 2004; Warburton, Price, Swinburn, $\&$ Wise, 1999). Therefore, in the present study, significant improvement (in German) after CIAT was not only accompanied by enhanced activity in the previously (at the first investigation) activated areas but rather resulted in a bilateral (re-) recruitment in areas that had not been activated by the naming task. The fact that both hemispheres were involved in improved task performance was possibly mediated by the aforementioned more bilateral organization of language networks in bilinguals.

We did not include a repeated baseline assessment of language functions and associated brain activation patterns in the present case study - still, the patient was in the late chronic stage of aphasia and one would not expect substantial spontaneous improvement of language functions without training (Robey, 1998). Moreover, improvement was found (a) within a very short time interval and (b) was evident not only in a single isolated test, but rather in two naming tests (in- and outside of the scanner) and in the AAT. Moreover, only recently we assessed the stability of connected speech measures in 16 patients with chronic aphasia across repeated baseline sessions (Barthel, Djundja, Meinzer, Rockstroh, \& Eulitz, 2006). Language functions were comparable across the baseline interval ( 2 days), while significant improvement was substantiated in a third test following 2 weeks of intensive language training. Concerning the stability of the fMRI results: stability of performance and brain activation across repeated fMRI scans has been demonstrated in two recent studies testing chronic aphasic patients during a non-verbal semantic (Kurland et al., 2004) and object naming task (Fridriksson, Morrow-Odom, Moser, Fridriksson, \& Baylis, 2006). Moreover, in a previous single case report (Meinzer et al., 2006) we compared language functions in an aphasic patient and three healthy subjects using exactly the same fMRI design as in the present study and found no increased activation across the 2 -week time interval in (untrained) controls, whereas increased activation in the patient was associated with improved naming performance. Therefore, we are confident that 
the results/improvements across different language tests and the enhanced activation pattern for German compared to French are related to the training.

The fact that previous studies found no language differences in the brain regions associated with naming performance in early bilinguals without brain injury (e.g., Hernandez, Martinez, \& Kohnert, 2000) ties the changes in behavioral performance and brain activation pattern in this early bilingual aphasic patient even closer to the treatment provided exclusively in German. One explanation for the lack of treatment generalization to French could be that the picture naming task we used did not appeal to rule-governed phenomena (as would morphosyntactic and phonological tasks). Therefore, one would not necessarily expect transfer to the untreated language, with the possible exception of cognates (Detry et al., 2005; Kohnert, 2004; Lalor \& Kirsner, 2001; Roberts \& Deslauriers, 1999). Even though the present study was not specifically designed to elucidate the influence of cognate nouns on naming performance, 26 of the 80 stimuli that were used for fMRI stimulation were cognate nouns [e.g., German-French (English): Rasierer-rasoir (shaver), Bank-banc (bench), Kaenguru-kangourou (kangaroo)]. Still, at the first investigation the patient correctly named four pictures in French, only one of which was classified as a cognate [Harfe-harpe (harfe)]. After treatment the number of correct responses during the French version of the fMRI naming task was comparably low as during the first assessment (six correct responses, including three cognates). Given that 12 of the 26 cognates that were part of the stimulus set during fMRI were trained once a day [during intensive German language training], the improvement is apparently low for cognates and non-cognates. Basically no advantage was found for the naming of cognates nouns at the first investigation or after daily intensive training, which also included a substantial number of cognates.

Moreover, from a more psycholinguistic perspective several theoretical models of language processing in bilinguals (e.g., Dijkstra, Grainger, \& van Heuven, 1999) assume shared conceptual lexical representations for different languages. Under the assumption of automatic coactivation of word forms and/or phonological aspects of competing languages a considerable activation in the French naming condition should have been observed. Even though tentative, the results of the present case report seem to argue rather for a more direct access to conceptual information for each language. This would be in line with the assumption, that only in the early stages of (second) language acquisition access to meaning is mediated by the first language, while in later stages a more direct route might be used (Kroll \& Tokowicz, 2001).

In sum, the present case study represents a promising example of use and/or training-related differential recovery of expressive language functions and concomitant functional brain reorganization which might be explained by Hebbian learning, i.e., the progressive use of a single language may functionally enhance its network without improving the other language. Interestingly, it has been shown that healthy (unbalanced) bilinguals during picture naming in their non-dominant language may be unable to inhibit activation of the picture name in their native language
(Hermans, Bongaerts, de Bot, \& Schreuder, 1998). This has been linked to enhanced recovery of the native language in bilingual aphasics following treatment (Hinckley, 2003; Lalor \& Kirsner, 2001), in the sense, that picture naming treatment in aphasia (even though provided in both languages) results in more frequent activation of the native language and concomitant greater improvement (cf. Hinckley, 2003). The same might be true for patients where only one language has been treated following stroke, as in the present case.

This was verified by the differential recovery due to long-term rehabilitation and further improvement after short-term intensive language training even in the late stage of aphasia, where no further spontaneous improvement is to be expected. Furthermore, it is believed that there is large overlap of brain regions associated with language production tasks in early bilinguals (Crinion et al., 2006; Hernandez et al., 2000; Kim, Relkin, Lee, $\&$ Hirsch, 1997). Therefore, the resulting differential recovery pattern of expressive language functions in German and French is even more striking and serves as a within-patient control condition. It allows attributing the differences between languages solely to (training-induced) reorganizational processes followings stroke.

\section{Acknowledgements}

This work was supported by the Deutsche Forschungsgemeinschaft (DFG, Grant RO 805/11-4) and the Kuratorium Zentrales Nervensystem (ZNS, Grant 2001013). J.O. is supported by a postdoctoral grant by the Landesstiftung Baden-Württemberg $\mathrm{GmbH}$. We gratefully acknowledge the support of D. Djundja, R. Assadollahi, and T. Elbert.

\section{References}

Barthel, G., Djundja, D., Meinzer, M., Rockstroh, B., \& Eulitz, C. (2006). Aachen language analysis (ASPA): Evaluation in chronic aphasia. Sprache, Stimme, Gehör, 30(3), 103-110.

Brett, M., Leff, A. P., Rorden, C., \& Ashburner, J. (2001). Spatial normalization of brain images with focal lesions using cost function masking. Neuroimage, 14(2), 486-500.

Cappa, S. F. (2000). Neuroimaging of recovery from aphasia. Neuropsychological Rehabilitation, 10(3), 365-376.

Cardebat, D., Demonet, J. F., De Boissezon, X., Marie, N., Marie, R. M., Lambert, J., et al. (2003). Behavioral and neurofunctional changes over time in healthy and aphasic subjects: A PET Language Activation Study. Stroke, 34(12), 2900-2906.

Crinion, J., Turner, R., Grogan, A., Hanakawa, T., Noppeney, U., Devlin, J. T., et al. (2006). Language control in the bilingual brain. Science, 312(5779), 1537-1540.

Crosson, B., Moore, A. B., Gopinath, K., White, K. D., Wierenga, C. E., Gaiefsky, M. E., et al. (2005). Role of the right and left hemispheres in recovery of function during treatment of intention in aphasia. Journal of Cognitive Neuroscience, 17(3), 392-406.

Davis, G. A., \& Wilcox, M. J. (1985). Adult aphasia rehabilitation: Applied pragmatics. San Diego, CA: College-Hill Press.

Detry, C., Pillon, A., \& de Partz, M. P. (2005). A direct processing route to translate words from the first to the second language: Evidence from a case of a bilingual aphasic. Brain and Language, 95, 40-41.

Dijkstra, T., Grainger, J., \& van Heuven, W. J. B. (1999). Recognition of cognates and interlingual homographs: The neglected role of phonology. Journal of Memory and Language, 41, 496-518. 
Duffy. (1986). Schuell's stimulation approach in rehabilitation. In Chapey (Ed.), Language intervention strategies (pp. 187-214). Baltimore: Grune \& Stratton.

Edmonds, L. A., \& Kiran, S. (2006). Effect of semantic naming treatment on crosslinguistic generalization in bilingual aphasia. Journal of Speech, Language and Hearing Research, 49(4), 729-748.

Fabbro, F. (2001a). The bilingual brain: Bilingual aphasia. Brain and Language, $79(2), 201-210$

Fabbro, F. (2001b). The bilingual brain: Cerebral representation of languages. Brain and Language, 79(2), 211-222.

Fernandez, B., Cardebat, D., Demonet, J. F., Joseph, P. A., Mazaux, J. M., Barat, M., et al. (2004). Functional MRI follow-up study of language processes in healthy subjects and during recovery in a case of aphasia. Stroke, 35(9), 2171-2176.

Fiez, J. A., Raichle, M. E., Balota, D. A., Tallal, P., \& Petersen, S. E. (1996). PET activation of posterior temporal regions during auditory word presentation and verb generation. Cerebral Cortex, 6(1), 1-10

Filiputti, D., Tavano, A., Vorano, L., de Luca, G., \& Fabbro, F. (2002). Nonparallel recovery of languages in a quadrilingual aphasic patient. International Journal of Bilingualism, 6(4), 395-410.

Fredman, M. (1975). The effect of therapy given in Hebrew on the home language of the bilingual or polyglot adult aphasic in Israel. British Journal of Disorder Communication, 10(1), 61-69.

Fridriksson, J., Morrow-Odom, L., Moser, D., Fridriksson, A., \& Baylis, G. (2006). Neural recruitment associated with anomia treatment in aphasia. Neuroimage.

Fu, C. H., Vythelingum, G. N., Brammer, M. J., Williams, S. C., Amaro, E., Jr., Andrew, C. M., et al. (2006). An fMRI study of verbal self-monitoring: Neural correlates of auditory verbal feedback. Cerebral Cortex, 16(7), 969-977.

Gaab, N., Gabrieli, J. D. E., \& Glover, G. H. (2006). Assessing the influence of scanner background noise on auditory processing. I. An fMRI study comparing three experimental designs with varying degrees of scanner noise. Human Brain Mapping, doi:10.1002/hbm.20298.

Galvez, A., \& Hinckley, J. (2003). Transfer patterns of naming treatments in a case of bilingual aphasia. Brain and Language, 87, 173174.

Gil, M., \& Goral, M. (2004). Nonparallel recovery in bilingual aphasia: Effects of language choice, language proficiency and treatment. International Journal of Bilingualism, 8(2), 191-219.

Hall, D. A., Haggard, M. P., Akeroyd, M. A., Palmer, A. R., Summerfield, A. Q., Elliott, M. R., et al. (1999). "Sparse" temporal sampling in auditory fMRI. Human Brain Mapping, 7(3), 213-223.

Hermans, D., Bongaerts, T., de Bot, K., \& Schreuder, R. (1998). Producing words in a foreign language: Can speakers prevent interference from their first language? Bilingualism, 1, 213-229.

Hernandez, A. E., Martinez, A., \& Kohnert, K. (2000). In search of the language switch: An fMRI study of picture naming in Spanish-English bilinguals. Brain and Language, 73, 421-431.

Hinckley, J. (2003). Picture naming treatment inaphasia yields greater improvement in L1. Brain and Language, 87, 171-172.

Huber, H., Poek, K., Weniger, D., \& Willmes, K. (1983). Aachener Aphasie Test. Göttingen: Hogrefe.

Hull, R., \& Vaid, J. (2006). Laterality and language experience. Laterality, 11(5), 436-464.

Junque, C., Vendrell, P., Vendrell-Brucet, J. M., \& Tobena, A. (1989). Differential recovery in naming in bilingual aphasics. Brain and Language, 36(1), $16-22$.

Kerns, J. G., Cohen, J. D., MacDonald, A. W. 3rd, Cho, R. Y., Stenger, V. A., \& Carter, C. S. (2004). Anterior cingulate conflict monitoring and adjustments in control. Science, 303(5660), 1023-1026.

Kim, K. H., Relkin, N. R., Lee, K. M., \& Hirsch, J. (1997). Distinct cortical areas associated with native and second languages. Nature, 388(6638), 171-174.

Kohnert, K. (2004). Cognitive and cognate-based treatments for bilingual aphasia: A case study. Brain and Language, 91(3), 294-302.

Kroll, J. F., \& Tokowicz, N. (2001). The development of conceptual representation for words in a second language. In J. Nicol (Ed.), One mind, two languages: Bilingual language processing (pp. 49-71). Malden, MA: Blackwell Publishers.
Kurland, J., Naeser, M. A., Baker, E. H., Doron, K., Martin, P. I., Seekins, H. E., et al. (2004). Test-retest reliability of fMRI during nonverbal semantic decisions in moderate-severe nonfluent aphasia patients. Behavoural Neurology, 15(3-4), 87-97.

Laganaro, M., \& Overton-Venet, M. (2001). Acquired alexia in multilingual aphasia and computer-assisted treatment in both languages: Issues of generalisation and transfer. Folia Phoniatrica et Logopaedica, 53(3), 135-144.

Lalor, E., \& Kirsner, K. (2001). The role of cognates in bilingual aphasia: Implications for assessment and treatment. Aphasiology, 15, 1047-1056.

Lancaster, J. L., Woldorff, M. G., Parsons, L. M., Liotti, M., Freitas, C. S., Rainey, L., et al. (2000). Automated Talairach atlas labels for functional brain mapping. Human Brain Mapping, 10, 120-131.

Leger, A., Demonet, J. F., Ruff, S., Aithamon, B., Touyeras, B., Puel, M., et al. (2002). Neural substrates of spoken language rehabilitation in an aphasic patient: An fMRI study. Neuroimage, 17(1), 174-183.

Marrero, M. Z., Golden, C. J., \& Espe-Pfeifer, P. (2002). Bilingualsim, brain injury, and recovery: Implications for understanding the bilingual and for therapy. Clinical Psychology Review, 22, 463-478.

Meinzer, M., Djundja, D., Barthel, G., Elbert, T., \& Rockstroh, B. (2005). Long-term stability of improved language functions in chronic aphasia after constraint-induced aphasia therapy. Stroke, 36(7), 1462-1466.

Meinzer, M., Elbert, T., Wienbruch, C., Djundja, D., Barthel, G., \& Rockstroh, B. (2004). Intensive language training enhances brain plasticity in chronic aphasia. BMC Biology, 2(1), 20.

Meinzer, M., Flaisch, T., Obleser, J., Assadollahi, R., Djundja, D., Barthel, G., et al. (2006). Brain regions essential for improved lexical access in an aged aphasic patient: A case report. BMC Neurology, 6(1), 28

Murtha, S., Chertkow, H., Beauregard, M., \& Evans, A. (1999). The neural substrate of picture naming. Journal of Cognitive Neuroscience, 11(4), 399-423.

Musso, M., Weiller, C., Kiebel, S., Muller, S. P., Bulau, P., \& Rijntjes, M. (1999). Training-induced brain plasticity in aphasia. Brain, 122(Pt 9), 1781-1790.

Naeser, M. A., Martin, P. I., Nicholas, M., Baker, E. H., Seekins, H., Kobayashi, M., et al. (2005). Improved picture naming in chronic aphasia after TMS to part of right Broca's area: An open-protocol study. Brain and Language, 93(1), 95-105.

Nickels, N. (2002). Therapy for naming disorders: Revisiting, revising and reviewing. Aphasiology, 16, 935-979.

Pallier, C., Dehaene, S., Poline, J. B., LeBihan, D., Argenti, A. M., Dupoux, E., et al. (2003). Brain imaging of language plasticity in adopted adults: Can a second language replace the first? Cerebral Cortex, 13(2), 155161

Paradis, M. (1987). The assessment of bilingual aphasia. Hillsdale, NJ: Erlbaum. Paradis, M. (2001). Assessing bilingual aphasia. In B. Uzzell, \& A. Ardila (Eds.), Handbook of cross-cultural neuropsychology (2nd ed.). Mahwah: Erlbaum.

Pearce, J. M. (2005). A note on aphasia in bilingual patients: Pitres' and Ribot's laws. European Neurology, 54(3), 127-131.

Perani, D., Cappa, S. F., Tettamanti, M., Rosa, M., Scifo, P., Miozzo, A., et al. (2003). A fMRI study of word retrieval in aphasia. Brain and Language, 85(3), 357-368.

Price, C. J., Mummery, C. J., Moore, C. J., Frakowiak, R. S., \& Friston, K. J. (1999). Delineating necessary and sufficient neural systems with functional imaging studies of neuropsychological patients. Journal of Cognitive Neuroscience, 11(4), 371-382.

Pulvermuller, F., Hauk, O., Zohsel, K., Neininger, B., \& Mohr, B. (2005). Therapy-related reorganization of language in both hemispheres of patients with chronic aphasia. Neuroimage, 28(2), 481-489.

Pulvermueller, F., Neininger, B., Elbert, T., Mohr, B., Rockstroh, B., Koebbel, P., et al. (2001). Constraint-induced therapy of chronic aphasia after stroke. Stroke, 32(7), 1621-1626.

Roberts, P. M., \& Deslauriers, L. (1999). Picture naming of cognate and noncognate nouns in bilingual aphasia. Journal of Communication Disorders, $32(1), 1-22$

Robey, R. R. (1998). A meta-analysis of clinical outcomes in the treatment of aphasia. Journal of Speech, Language and Hearing Research, 41(1), $172-187$.

Sharp, D. J., Scott, S. K., \& Wise, R. J. (2004). Retrieving meaning after temporal lobe infarction: The role of the basal language area. Annals of Neurology, $56(6), 836-846$ 
Szekely, A., Jacobsen, T., D'Amico, S., Devescovi, A. A. A. E. H. D., et al. (2004). A new on-line resource for psycholinguistic studies. Journal of Memory and Language, 51(2), 247-250.

Talairach, P., \& Tournoux, J. (1988). A stereotactic coplanar atlas of the human brain. Stuttgart: Thieme.
Warburton, E., Price, C. J., Swinburn, K., \& Wise, R. J. (1999). Mechanisms of recovery from aphasia: Evidence from positron emission tomography studies. Journal of Neurology, Neurosurgery, and Psychiatry, 66(2), 155-161. Watamori, T. S., \& Sasanuma, S. (1978). The recovery processes of two English-Japanese bilingual aphasics. Brain and Language, 6(2), 127-140. 